341

\section{ARE INTERNAL MEDICINE RESIDENT PHYSICIANS ADHERING TO COLORECTAL CANCER SCREENING RECOMMENDATIONS}

Laith H. Jamil, M.D., Ghassan Bachuwa, M.D.*, Asif Ishaque, M.D., Sami Rishmawi, M.D., Mada Karmo, M.D. Mayo Clinic, Rochester, MN; Michigan State Univ., Hurley Medical Center, Flint, MI; University of Michigan, Ann Arbor, MI and Wayne State University, Detroit, MI.

Purpose: 1-Determine whether internal medicine resident physicians were adhering to the current recommendations for colorectal cancer screening issued by the Agency for Health Care Policy and Research, (AHCPR), 1997. 2-Determine whether patient's sex, race or age influenced colorectal cancer screening. 3-To determine is there a relationship between the resident physician's sex or post-graduate year (PGY) level and adherence to these recommendations. 4-Proper documentation and its relation to resident physician's sex or PGY level.

Methods: Retrospective chart review of 230 patients, 55 years of age and above, who received care at the Flint Ambulatory Health Clinic at Hurley Medical Center, Flint, MI, from a resident physician between 1/1/1999 and 6/30/2000.

Results: Overall $60 \%$ of patients were offered some form of screening. Only $46 \%$ had a screening test performed. 67 (29\%) patients had fecal occult blood testing (FOBT). 45 (20\%) patients had flexible sigmoidoscopy (FSIG), of whom 25 had the procedure performed by a male physician $(\mathrm{P}=0.01) .8 \%$ had colonoscopy, $8 \%$ had both FOBT and FSIG. Out of 125 patients that had no form of screening, $26 \%$ were offered FSIG but declined. There was a significant relationship between higher PGY level and proper documentation $(\mathrm{P}=0.02)$. There was no other statistically significant difference when comparing the various screening tests to patient's sex, age and race, resident physician's sex or by PGY level.

Conclusions: Despite continuous emphasis on primary care and prevention in residency programs, screening for colorectal cancer among medical residents remains suboptimal. Further studies are needed to evaluate methods to increase implementation of cancer screening guidelines.

\section{2}

\section{CLINICAL OUTCOMES OF MEDICAL OR SURGICAL THERAPY IN PATIENTS BELOW AGE 40 WITH ACUTE DIVERTICULITIS}

Andra S. Greenberg, B.S., Robert Gal, M.D., Robert M. Coben, M.D., Sidney Cohen, M.D., Anthony J. DiMarino, Jr., M.D., FACG*. Thomas Jefferson University, Philadelphia, PA and Underwood-Memorial Hospital, Woodbury, NJ.

Purpose: Although acute diverticulitis is well-recognized in younger patients (below 40 years), management remains controversial. The aim of this study was: (A) to perform a retrospective chart analysis of clinical outcomes in all patients aged 40 or younger with diverticulitis evaluated at a university and an affiliated community hospital between 1991 and 2002; (B) to define recommendations on management based on this outcomes study.

Methods: One-hundred forty-nine patients aged 40 and younger with confirmed diverticulitis on computerized tomography, barium enema, or surgical pathology were identified; of these cases, 50 were available for follow-up by direct contact after at least one year. The patients were divided into two groups based upon whether they initially were treated with antibiotics $(n=30)$ or had surgical management (segmental resection of diseased colon) $(n=20)$ after their first episode. The groups subsequently were analyzed to evaluate a potential relationship between the total number of diverticulitis recurrences, and white blood cell count, temperature, age, and gender.

Results: For the 20 patients in whom surgical resection was performed at or soon after presentation, three $(15 \%)$ had a recurrence of diverticulitis (mean follow-up 6.89 years, median 6.04 years). In the medically-treated group, 17 patients $(57 \%)$ had a recurrence, while 13 (43\%) did not recur (mean follow-up 5.72 years, median 4.75 years). This difference in recurrence rate is significant $(\mathrm{p}=0.004)$. The two treatment groups were not significantly different with regard to white blood cell count, temperature, or age. No significant correlation was found between the number of recurrences and any of the three variables: white blood cell count (Spearman correlation coefficient $(\mathrm{Scc})=-0.17, \mathrm{p}=0.244)$, temperature $(\mathrm{Scc}=$ $-0.02, \mathrm{p}=0.895)$, and age $(\mathrm{Scc}=0.15, \mathrm{p}=0.278)$. The difference in the total number of recurrences between males and females was not significant $(\mathrm{p}=0.212)$.

Conclusions: (A) Diverticulitis in patients under age 40 does occur and should be suspected in this age group; (B) surgical treatment is effective but disease may recur in a minority of patients; (C) medical treatment also is effective initial therapy, with almost half of patients remaining without recurrence in follow-up; (D) this outcome study suggests that therapeutic options must be individualized since criteria for choice of initial treatment are not evident at this time.

343

PREVALENCE OF SIGNIFICANT PROXIMAL COLORECTAL NEOPLASIA IN PATIENTS WITH LARGE PROXIMAL HYPERPLASTIC POLYPS

Haleh Vaziri, M.D., Joseph C. Anderson, M.D. *, Zvi Alpern, M.D., Patricia Ells, A.N.P. Stony Brook University, Stony Brook, NY.

Purpose: Hyperplastic (HP) polyps have been considered non-neoplastic lesions lacking malignant potential, most of which never grow larger than $0.5 \mathrm{~cm}$ and are usually located in the distal colon and rectum. Large HP polyps share common risk factors with other adenomatous lesions and they be more clinically important than the small HP polyps. Large HP polyps may be markers for more important adenomatous lesions. Our crosssectional study was designed to determine the association between proximal large hyperplastic polyps and the risk of synchronous proximal significant neoplasia.

Methods: Data was gathered from 1988 consecutive screening colonoscopies. Demographics collected include age, gender, smoking habits, alcohol consumption, history of IBD, endoscopic finding on examination and pathology reports of removed polyps. HP polyps were considered large if they were more than $1 \mathrm{~cm}$. Splenic flexure was the dividing point between proximal and distal colon. Patients were categorized into 3 groups: 1) Large proximal HP polyps; 2) Large distal HP polyps; 3) No large HP polyps. Significant neoplasia was defined as multiple $(>2)$, large $(>1 \mathrm{~cm})$ adenoma, any villous adenoma, high grade dysplasia and adenocarcinoma. All the results are adjusted for age, gender and family history.

Results: Of the 1988 patients who underwent colonoscopy, 39 had large hyperplastic polyp $(1.97 \%) 41 \%$ of which were located in the proximal colon. Patients with large right sided hyperplastic polyps had a higher prevalence of proximal significant neoplasia ( $p: 0.019)$. There was no statistical difference between patients with distal large hyperplastic polyps and patients without large hyperplastic polyps.

Synchroneous Proximal Significant Neoplasia in Patients with Hyperplastic Polyps

\begin{tabular}{cccccc} 
Polyp Type & $\begin{array}{c}\text { Total } \\
\text { Number }\end{array}$ & $\begin{array}{c}\text { Proximal } \\
\text { Neoplasia }\end{array}$ & OR & CI & P Value \\
\hline $\begin{array}{c}\text { Proximal Large } \\
\text { HP Polyp }\end{array}$ & 16 & 3 & 6.3 & $1.73-22.7$ & $\mathbf{0 . 0 1 9}$ \\
$\begin{array}{c}\text { Distal Large } \\
\text { HP Polyp }\end{array}$ & 23 & 2 & 2.2 & $0.8-12.3$ & 0.32 \\
$\begin{array}{c}\text { No Large HP } \\
\text { Polyp }\end{array}$ & 1934 & 67 & 1 & N/A & N/A \\
\hline
\end{tabular}

Conclusions: Our study suggests that although the incidence of right sided hyperplastic polyps is low, these lesions may predict the presence of more ominous neoplasia. Surveillance of individuals with these lesions may need to be intensified as they may be the predictors of synchronous proximal neoplasia. 